\title{
ESTUDO PETROGRÁFICO DO SUPORTE ROCHOSO DO SÍTIO ARQUEOLÓGICO DA PEDRA DO INGÁ, PB
}

\author{
Lucila E. P. Borges ${ }^{1}$, Claristella A. dos Santos ${ }^{2}$, Felisbela M. C. Oliveira ${ }^{3}$, \\ Maria da Conceição S. M. Lage ${ }^{4}$
}

1 - Professora, Dep. Geologia, UFPE; 2 - Arqueóloga Doutora, Núcleo de Estudos Indígenas, Dep. Letras, UFPE; 3 - Professora, Programa de Pós-Graduação em Engenharia Mineral, UFPE; 4 - Professora,Dep. Química, CCN, UFPI; ester@ufpe.br

\begin{abstract}
Resumo: Este artigo apresenta o estudo do suporte rochoso do sítio arqueológico Pedra do Ingá (PB).Os resultados do presente estudo visam contribuir prioritariamente para a adoção de medidas conservacionistas pautadas nas propriedades petrográficas desse sítio em face aos agentes exógenos. Nesse sentido, esta pesquisa estuda as características petrográficas do suporte rochoso da Pedra do Ingá. Essa caracterização foi realizada em amostras coletadas no entorno deste sítio. A análise das lâminas releva a existência de Biotita-granodiorito, rocha ígnea de textura compacta, granulação fina, equigranular, isotrópica de alta dureza. O quartzo ocorre com percentual de 30\%, plagioclásios com $30 \%$, feldspatos potássicos apresentam $24 \%$ o que é característico de rochas ígneas compostas por quartzo e feldspatos. A biotita é o principal mineral máfico e somados a ela ocorre, epidoto, zircão e minerais opacos. O plagioclásio mostra processo de alteração para micas finas, denominado sericitização. A biotita apresenta alteração para cloritas. Fatores intrínsecos (como composição mineralógica, textura e porosidade) e extrínsecos (como quantidade de água, temperatura, pH, potencial de oxi-redução e forças bióticas) contribuem para a degradação e decomposição da rocha. A presença do Riacho Bacamarte fornece a água, veículo importante nas reações de hidratação, hidrólise, oxidação e também na dissolução de minerais, alterando assim os minerais presentes no suporte, mas também atenua os efeitos da termoclastia que causa o desplacamento do suporte rochoso do referido sítio arqueológico.
\end{abstract}

Palavras Chave: sítios arqueológicos; suporte rochoso; processos de alteração

Abstract: PETROGRAPHIC STUDY OF THE ROCKY SUPPORT OF THE ARCHAEOLOGICAL SITE OF PEDRA DO INGÁ, PB. This paper presents the study for the rock support of the archaeological site Pedra do Ingá (PB). The results of this study are intended to contribute primarily for the adoption of conservation measures guided by the petrographic properties of this site in face of exogenous agents. In this sense, this research studies the petrographic features of the rock support of Pedra do Ingá. This characterization was performed on samples collected in the surrounding areas of this site. Slide analysis highlights the existence of biotite-granodiorite, igneous rock of compact texture, finegrained, equigranular, high hardness isotropic. Quartz occurs with a percentage of $30 \%$, plagioclase with $30 \%$, potassic feldspar have $24 \%$ which is characteristic of igneous rocks composed by quartz and feldspar. The biotite is the main mafic mineral and added to thereareepidote, zircon and opaque minerals. The plagioclase shows alteration process for fine mica, called sericitization. The biotite shows alteration to chlorite. Intrinsic factors (such as mineral composition, texture and porosity) as well as extrinsic factors (such as the amount of water, temperature, $\mathrm{pH}$, redox potential and biotic forces) contribute to the degradation and decomposition of the rock. The presence of Bacamarte Stream provides water, an important vehicle in the hydration reactions, hydrolysis, oxidation and also in the dissolution of minerals, thereby altering the minerals present in the support, but also mitigates the effects of termoclastia, which causes the peeling of the rock support of this archaeological site.

Keywords: archaeological sites; Rock support; alteration processes

\section{INTRODUÇÃO}

A preocupação principal desta pesquisa foi a de caracterizar o suporte rochoso deste sítio arqueológico, Pedra do Ingá, com vistas a subsidiar uma reflexão objetiva acerca dos mecanismos possíveis de preservação e monitoramento desse patrimônio. Este sítio de gravuras rupestres está submetido a condições específicas que devem ser ponderadas: a) estar situado no leito de um curso d'água, recebendo, portanto, ainda que durante um curto período do ano, os impactos diretos das águas que descem o riacho Bacamarte, b) receber durante o período chuvoso o impacto das águas pluviais, e; c) estar exposto durante todo o ano aos impactos diretos dos raios solares e às oscilações de amplitude térmica. Tais fatores exógenos e impactantes dialogam com as propriedades intrínsecas do suporte petrológico do referido sítio, necessitando, à vista disso, serem analisados.

O presente trabalho apresenta os resultados da avaliação das análises petrográficas realizados em material oriundo do sítio arqueológico Pedra do Ingá, localizado em região semiárida, no município de Ingá, na Paraíba. Este sítio, de projeção nacional, foi tombado pelo então Serviço do Patrimônio Histórico e Artístico Nacional (SPHAN), atual Instituto do Patrimônio Histórico e Artístico Nacional (IPHAN) em 30 de novembro de 1944. Nos últimos anos este sítio vem sofrendo um paulatino processo de degradação devido a ações de ordem natural e antrópica, razão pela qual a preservação deste patrimônio pré-histórico tem sido alvo de preocupação do IPHAN (Instituto do Patrimônio Histórico e Artístico Nacional) e da arqueologia brasileira.

A macroidentificação de rochas em sítios rupestres a partir de suas características aparentes tem sido o procedimento mais frequente no estudo da arte rupestre brasileira, sendo comum também o reconhecimento da rocha através da contextualização do sítio em mapa geológico. A identificação do suporte rochoso, através do estudo de lâminas petrográficas, ainda não é um procedimento rotineiro. No entanto esse tipo de 
análise deve se constituir em um método básico para o estudo da preservação de sítios rupestres.

\section{LOCALIZAÇÃO E GEOLOGIA}

O município de Ingá (Figura 1) está localizado na região do semiárido do estado da Paraíba, cerca de 84,4 Km da capital, João Pessoa. Ingá está inserido na Mesorregião do Agreste Paraibano e na Microrregião de Itabaiana. Do ponto de vista fisiográfico/geomorfológico o município está implantado na Depressão Sertaneja em uma área marcada por um relevo suave-ondulado, com ocorrência de vales estreitos e vertentes dissecadas (MASCARENHAS et al., 2005). A Depressão Sertaneja está contida na Província da Borborema, e reflete, deste modo, o quadro residual dos movimentos tectônicos, dobramentos, falhas e dissecações ocorridas em escala geológica em toda região semiárida do Nordeste do Brasil. Ainda segundo Mascarenhas et al. (2005), em termos da vegetação, a área do município é dominada pela caatinga hiperxerófila, com ocorrência ainda de floresta caducifólea, natural no cenário do clima Tropical Semiárido e de um quadro de oscilação pluviométrica com média de 431,8mm.

A bacia do rio Paraíba, com seus tributários, é a principal rede de drenagem que corta o município, entre suas porções média e baixa. A Pedra do Ingá está situada no leito desse rio, e recebe os impactos de suas águas durante um curto período de tempo ao longo do ano, por ser este um rio temporário.

Em termos geológicos a Pedra do Ingá faz parte da Suíte intrusiva Dona Inês (NP3 $\gamma 3$ di), cartograficamente está localizada na Folha Campina Grande - SB.25-Y-C-I, com escala 1:100.000 (Figura 1).

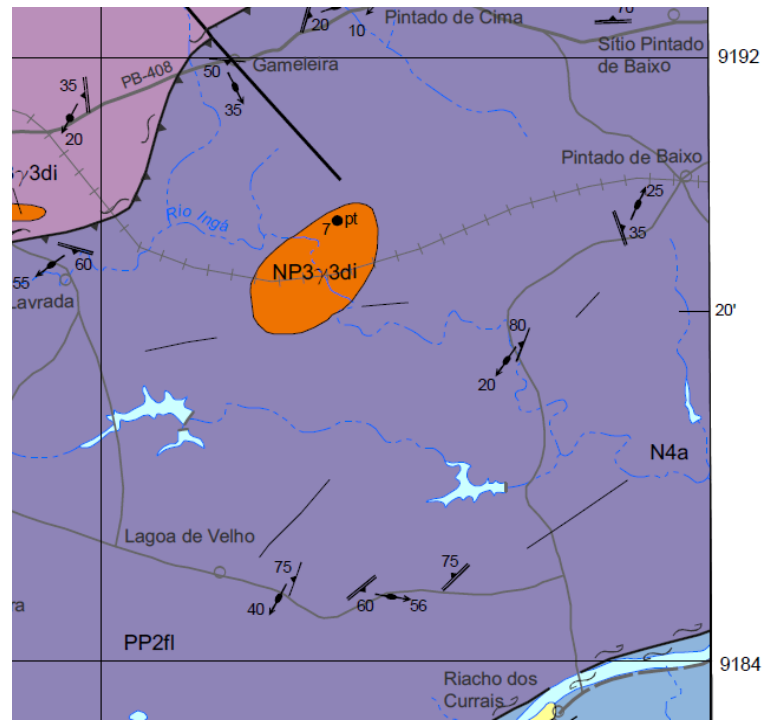

Figura 1. Situação da Pedra do Ingá em mapa geológico. Fonte:geobank.sa.cprm. gov.br

\section{ANÁLISE PETROLÓGICA DO SÍTIO PEDRA DO INGÁ}

A fim de efetuar os estudos petrográficos, foram coletadas no sítio Pedra do Ingá quatro (04) amostras de rocha integrantes do composto pétreo formador desse sítio. Dadas as semelhanças das características composicionais das amostras coletadas, optou-se pela realização de lâmina em apenas uma das amostras.

Foi realizado o estudo petrográfico em lâmina delgada confeccionada a partir deste material. Esta análise permitiu as caracterizações descritas a seguir. A partir da descrição macroscópica, o material é identificado como Biotita-granodiorito; rocha ígnea de textura compacta (alta coesão), granulação fina, equigranular, isotrópica de alta dureza (característico de rochas ígneas compostas por quartzo e feldspatos). Trata-se de uma rocha fanerítica, holocristalina, ou seja totalmente cristalina, de coloração rósea, apresentando a seguinte composição mineralógica: quartzo, plagioclásio, feldspato potássico, biotita, zircão, allanita, epídoto e minerais opacos. O mineral máfico dominante é a biotita; em relação aos félsicos dominantes, se destacam os minerais essenciais: quartzo, plagioclásio e feldspato potássico. A rocha não apresenta foliação.

As caraterísticas petrográficas observadas em lâmina delgada são colocadas a seguir: rocha leucocrática onde os minerais essenciais correspondem ao quartzo, feldspato potássico e plagioclásio. A biotita é o principal mineral máfico e somados a ela ocorre, epidoto, zircão e minerais opacos. O plagioclásio mostra frequentemente um processo de alteração para micas finas, denominado sericitização. A biotita apresenta um processo de alteração para cloritas, denominado cloritização. A textura é equigranular de granulação fina. A composição modal estimada dos minerais em seção delgada é: Quartzo $\pm 30 \%$; Plagioclásio $\pm 30 \%$; Feldspato Potássico $\pm 24 \%$; Biotita $\pm 15 \%$; Zircão, Opacos, Allanita, e Epidoto, observados traços; Minerais opacos, menos de $1 \%$.

As seguintes observações foram descritas com base na seção delgada: Quartzo: ocorre como cristais xenomórficos pequenos a médios, preenchendo espaços intersticiais (espaço entre os outros minerais); Biotita: ocorre como palhetas com cores variando do marrom claro ao marrom escuro sendo o constituinte máfico principal e nela ocorrem inclusões de zircão, epidoto e allanita. Apresenta um processo inicial de cloritização; Plagioclásio: ocorre como cristais bem formados com geminação polissintética (Lei da Albita e da Periclina) características. Alguns cristais mostram-se alterados para sericita. Mimerquita no contato com feldspato 
potássico é localmente observada; Feldspato potássico: ocorrem como cristais bem formados correspondendo a microclina com geminação cruzada e alguns cristais de ortoclásio com geminação Carlsbad. Alguns cristais mostram-se com textura gráfica.

A seguir, mostram-se fotos da descrição petrográfica, figuras 2 e 3 .
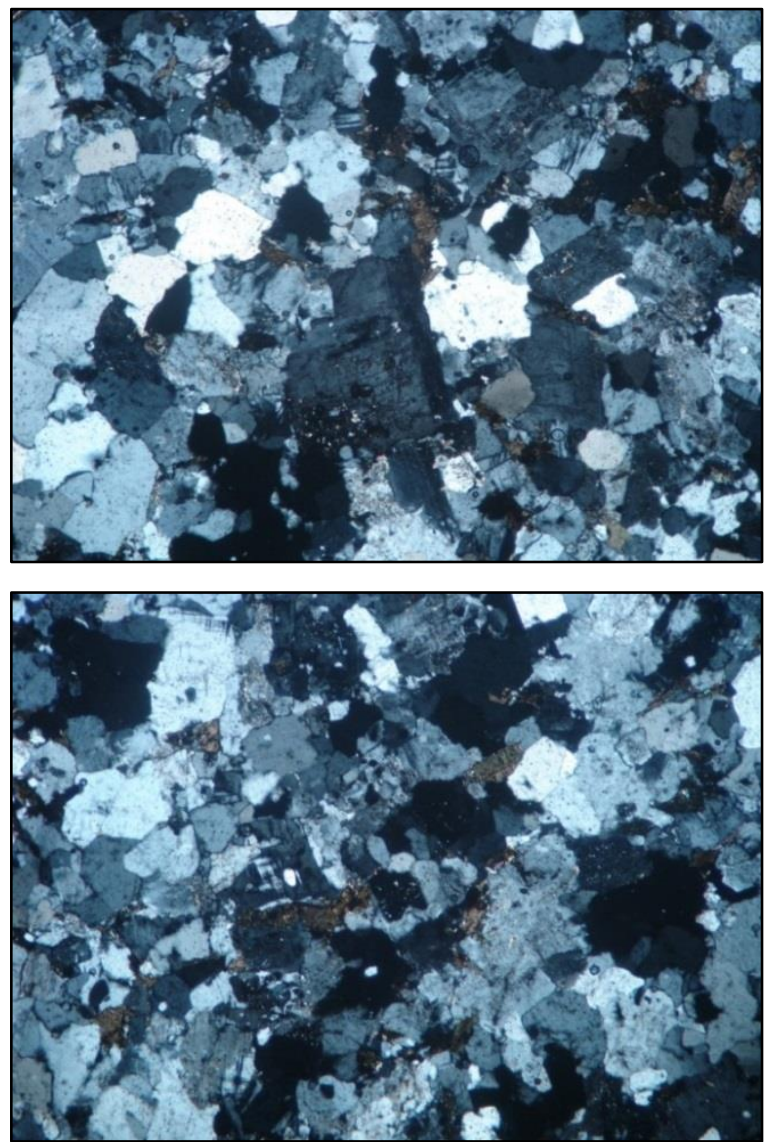

Figura 2. Fotomicrografia do aspecto geral da rocha, cristais grandes de plagioclásio sericitizado (no centro da foto), associado com quartzo e biotita. (NX - Aumento $4 X$ ), acima; Fotomicrografia do aspecto geral da rocha, cristais menores de microclina com característica geminação xadrez. (NX - Aumento 4X), abaixo. Fotomicrografia: Lucila Borges

\section{IMPLICAÇÕES DA COMPOSIÇÃO MINERALÓGICA E A CONSERVAÇÃO DO SÍTIO ARQUEOLÓGICO}

Alguns aspectos devem ser considerados na análise de qualquer suporte rochoso. Em primeiro lugar, todas as rochas têm uma composição mineralógica, porosidade, densidade e granulação peculiares, o que implica em diferentes respostas em face aos fatores exógenos que acometem os sítios rupestres. Em relação à amplitude térmica, por exemplo, cada espécie mineral reage de maneira distinta às diferenças de temperatura porque apresentam coeficientes de dilatação térmica diferentes.
O conhecimento dessas propriedades em um sítio rupestre é fundamental para se avaliar as possíveis respostas de um suporte rochoso aos fatores exógenos e que refletem, naturalmente, no seu grau de conservação. A longevidade de um sítio rupestre responde a esse contexto.
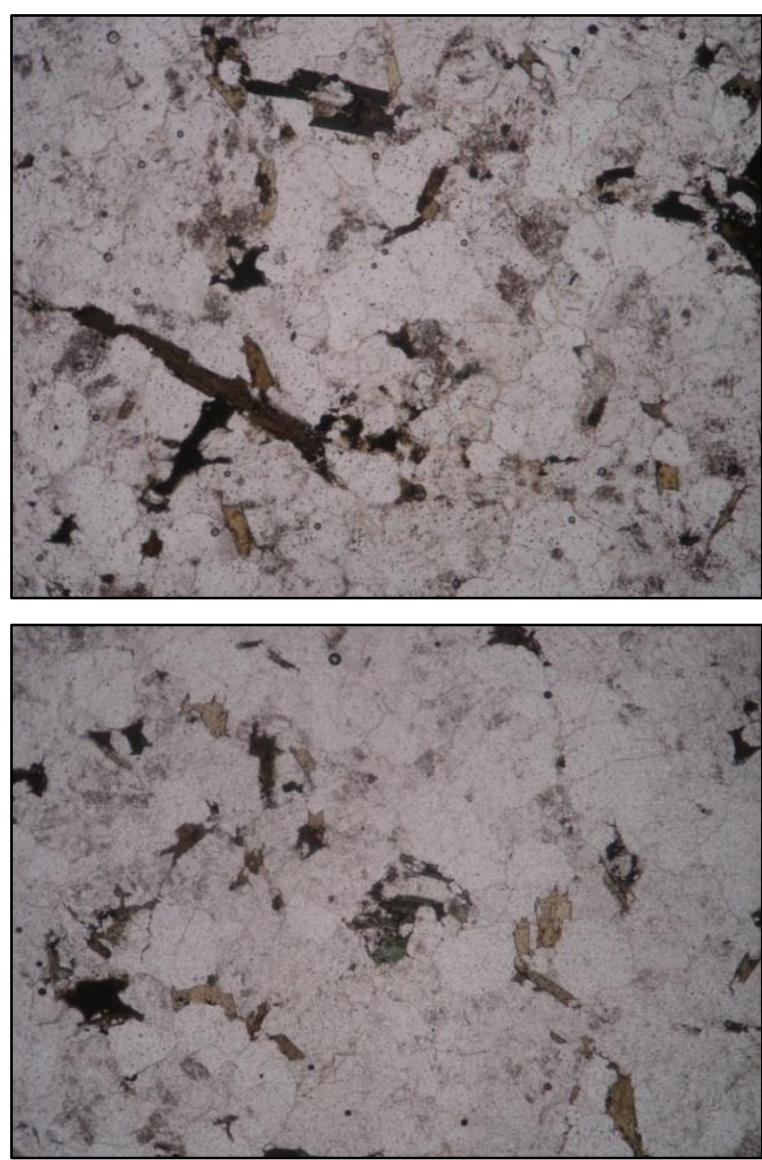

Figura 3. Fotomicrografia de cristais lamelares de biotita. (N// Aumento 4X), acima; Fotomicrografia de cloritização da biotita no centro da imagem, abaixo. Fotomicrografia: Lucila Borges

À vista disso, conclui-se que a alteração das rochas ocorre inexoravelmente.

Contudo sua maior ou menor intensidade depende de fatores intrínsecos e extrínsecos à rocha. Os fatores intrínsecos dependem do tipo de rocha e os extrínsecos são função do meio em que se processa a alteração. Dentre os fatores intrínsecos, tem-se a natureza do material (composição mineralógica), fissuras e porosidade, ou seja, sendo os últimos fatores que possibilitem maior área de ataque. Assim quanto maior a porosidade e a absorção de água, maior a possibilidade dos processos de alteração se instalar no material. No que diz respeito aos fatores extrínsecos, citam-se a temperatura, potencial de hidrogênio $(\mathrm{pH})$, potencial de oxi-redução (Eh), quantidade de água e forças bióticas.

A susceptibilidade dos minerais à alteração química é inversa à ordem de cristalização desses minerais, no magma. De acordo com a série de 
Goldich, que é visualizada abaixo, entre os minerais silicáticos mais vulneráveis situa-se a olivina, seguindo-se o plagioclásio cálcico, os piroxênios, os anfibólios, etc. Como se pode observar nesta mesma figura, os feldspatos potássicos e a moscovita já apresentam um maior grau de resistência, sendo, no entanto, o quartzo o mais estável.

No gráfico, confirma-se o que foi referido anteriormente, para além de evidenciar, a transformação dos feldspatos, notadamente os plagioclásios, em produtos de alteração tais quais os processos de saussuritização. Os plagioclásios são susceptíveis à ação do intemperismo químico, sendo as variedades mais sódicas mais resistentes porém menos que a microclina (feldspato potássico). Os plagioclásios mais cálcicos perdem $\mathrm{Ca}$ e $\mathrm{Al}$, gerando albita e normalmente pequenos cristais de epidoto, sericita, carbonato e, às vezes também clorita, gerando aspecto poiquilítico, recebendo o nome de saussurita (processo de saussuritização). A alteração também pode gerar escapolita, prehnita, zeólitas, alofano, montmorilonita e caulinita.

O intemperismo envolve processos físicos, químicos e biológicos sendo difícil fazer generalizações sobre a taxa de intemperismo, isto é, a taxa de alteração da rocha. Vários estudos indicam, todavia, importantes dados sobre o problema sem resolvê-los por completo. Taxas de intemperismo podem ser obtidas pela medição direta do intemperismo em superfícies de rochas com idades conhecidas. Monumentos, pedras fundamentais e edifícios históricos são bons exemplos.

No caso do sítio de Pedra do Ingá, a água do rio facilita o processo de alteração. Normalmente, essas águas são naturalmente acidificadas por conta da matéria orgânica que é trazida em suspensão. Os ácidos atacam os feldspatos (principalmente os plagioclásios), micas, e outros minerais. As biotitas e os plagioclásios apresentam sinais de alteração traduzidos respectivamente pela sericita (no plagioclásio) e clorita (biotita).

No caso do sítio de Pedra do Ingá, a água do rio facilita o processo de alteração. Normalmente, essas águas são naturalmente acidificadas por conta da matéria orgânica que é trazida em suspensão. Os ácidos atacam os feldspatos (principalmente os plagioclásios), micas, e outros minerais. As biotitas e os plagioclásios apresentam sinais de alteração traduzidos respectivamente pela sericita (no plagioclásio) e clorita (biotita).

Os minerais silicatados (quartzo, feldspatos, micas, etc) são sais de ácido fraco $\left(\mathrm{H}_{4} \mathrm{SiO}_{4}\right)$ e bases fortes, em contato com a água acidificada, os silicatos sofrem hidrólise resultando em uma solução alcalina $\left(\mathrm{H}_{4} \mathrm{SiO}_{4}\right.$ praticamente indissociado e as bases muito dissociadas). As reações de hidrólise são também acompanhadas de processos de hidratação onde moléculas de água são incorporadas à estrutura do mineral transformando em outro mineral.

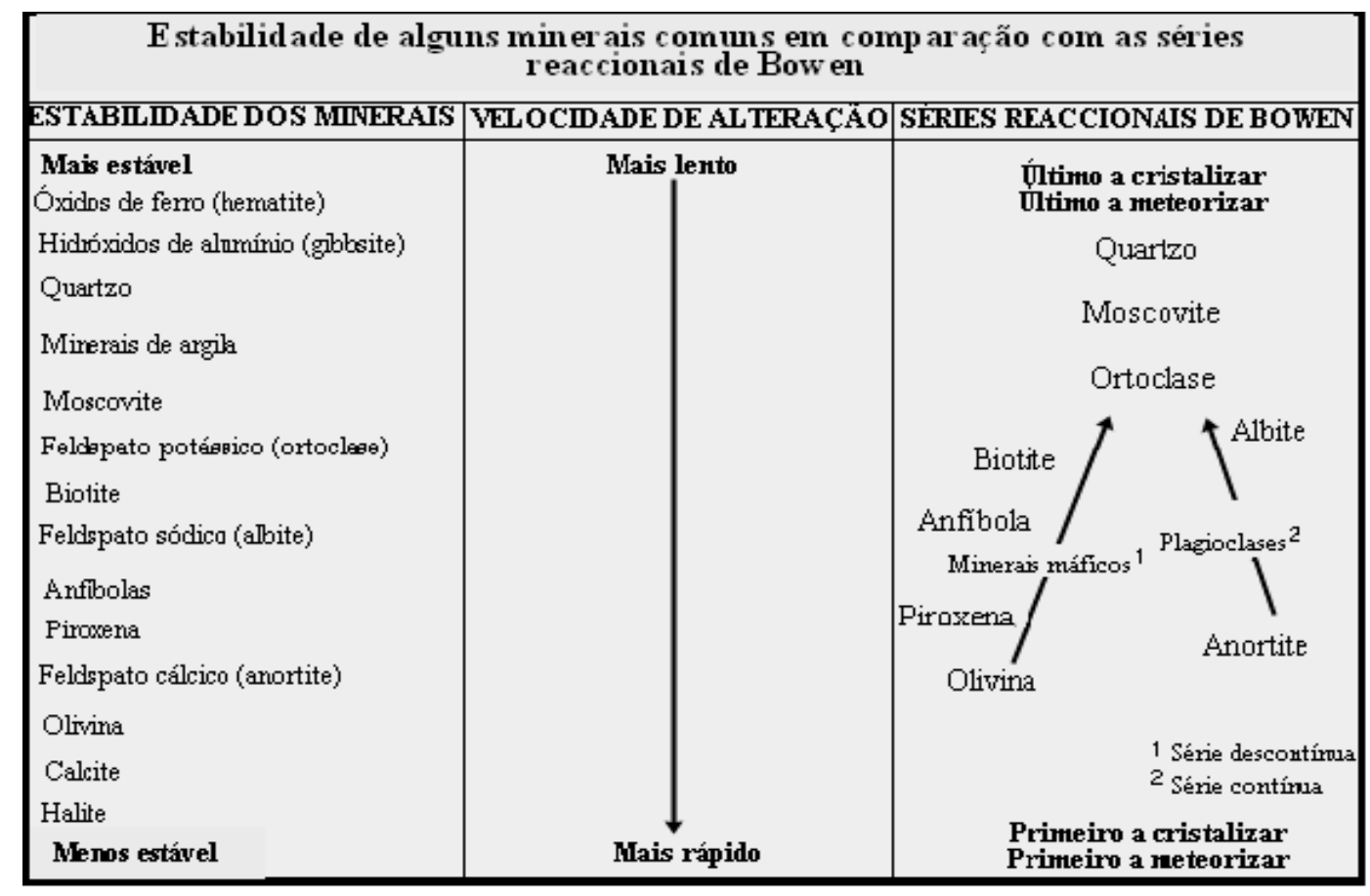

Figura 4. Série de Bowen e de Goldich. Estabilidade de minerais. Fonte: adaptada de: http://geodinamica.no.sapo.pt/html. 
A hidratação faz com que o mineral aumente de volume pela incorporação de moléculas de água. Este aumento de tamanho gera tensões no mineral que levam a fissuras. Além de hidrólise e hidratação, os minerais, envolvidos pela atmosfera terrestre, rica em oxigênio $\left(\mathrm{O}_{2}\right)$, podem se oxidar notadamente aqueles que possuem ferro ferroso em sua composição; tal fenômeno é potencializado pela presença de umidade e também induz ao aumento de massa do mineral pela incorporação de oxigênio à estrutura do mineral.

Com relação aos processos de alteração de natureza física, a termoclastia é um tipo de degradação provocada pela variação da temperatura na superfície das massas rochosas. A variação de temperatura na região da Pedra do Ingá é extremamente importante, pois, em um único dia, a diferença de temperatura entre o dia e a noite pode sofrer variação de mais de 10 graus centígrados. Este fenômeno de aquecimento/dilatação, resfriamento/contração repete-se diuturnamente e após milhares de ciclos a resistência do material rochoso fica comprometida, aparecendo as fissuras e esfoliações. A esfoliação gerada pela variação de temperatura põe em risco a conservação das inscrições na medida em que a descamação da rocha compromete o relevo das inscrições.
Com relação à composição mineralógica, o biotita-granodiorito, que constitui o suporte rochoso das inscrições de Pedra do Ingá, apresenta quartzo (30\%) e fedspatos (plagioclásio, 30\%, feldspato potássico, 24\%), estes minerais, o quartzo e o feldspato, dois dos minerais mais comuns nas rochas, têm coeficientes de dilatação muito diferentes. O quartzo, sob ação do calor do Sol, aumenta seu volume três vezes mais que o feldspato, e isso gera tensões nas rochas, o que acaba gerando fraturas.

Também, o alto percentual de quartzo que este suporte rochoso apresenta (30\%) indica uma maior propensão ao desplacamento. O quartzo é um mineral rúptil o que significa que a quando submetido a esforços (a dilatação gera aumento de tamanho e como o espaço do mineral é contido dentro da estrutura da rocha, há tensões que são geradas porque o mineral que se expandir mais não tem espaço) a energia proveniente da ação de deformação é armazenada no material e, como ele é rúptil, essa energia é usada para a quebra do mineral. Entretanto, por ser este suporte pétreo de textura equigranular e de granulação fina, pode este fator concorrer positivamente para não resultar em uma alta velocidade de desplacamento.

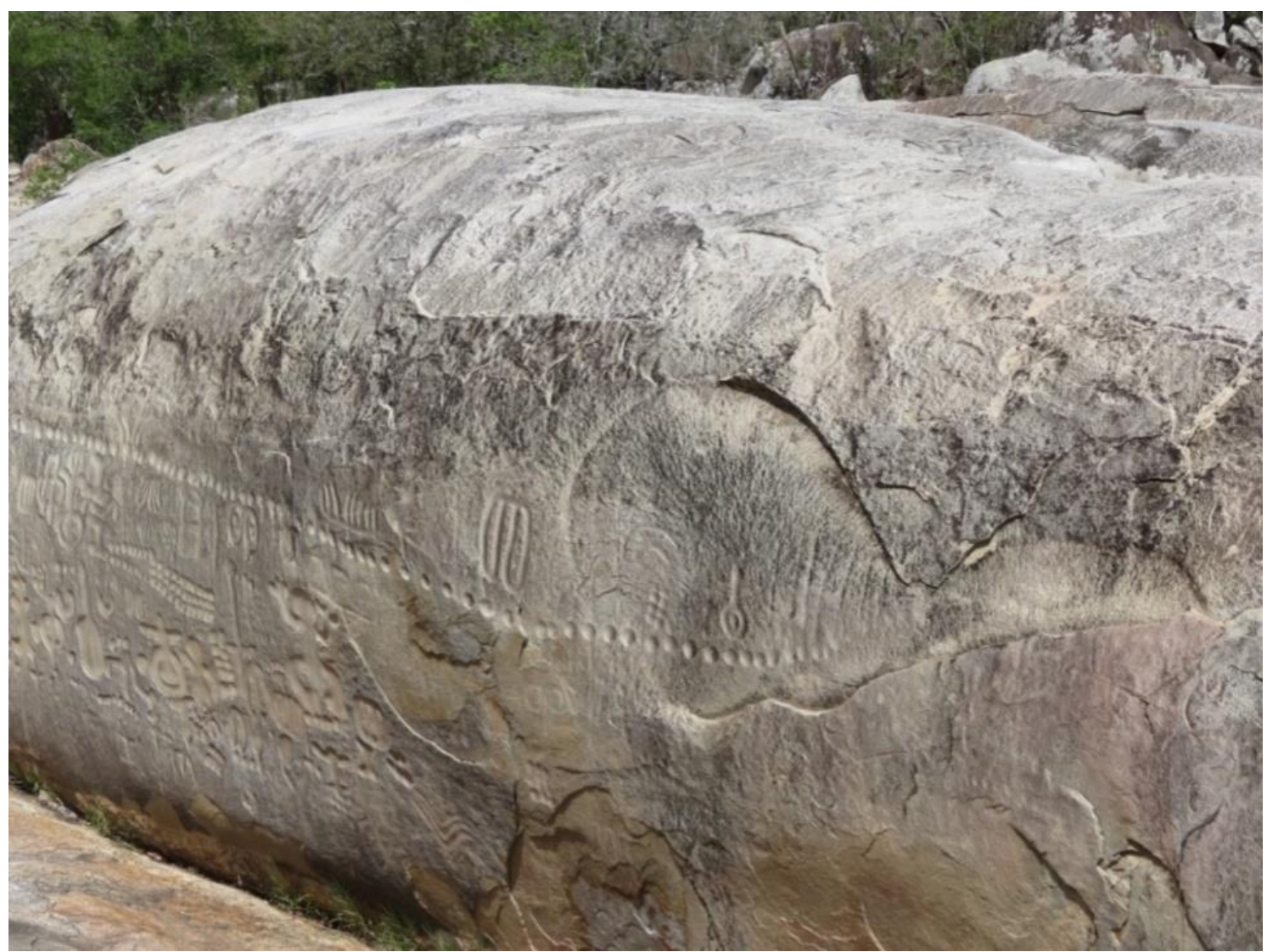

Figura 5. Desplacamento da rocha comprometendo o relevo das inscrições rupestres. 


\section{CONCLUSÕES}

O estudo petrográfico da Pedra do Ingá levou a conclusão de que o suporte rochoso desse sítio é um biotita granodiorito de textura fina. Sua composição mineralógica silicática, rica em quartzo e feldspatos (plagioclásios e potássicos), explica o desplacamento do suporte rochoso pela termoclastia: o coeficiente de dilatação do quartzo é três vezes maior que o dos feldspatos, o que gera tensões interminerais. Por outro lado, as reações químicas capazes de alterar estes minerais acontecem principalmente quando a água está presente: hidrólise, hidratação e oxidação. Os dois últimos tipos de reações se processam com a incorporação de massa que gera tensões intra minerais, fissurando estes mesmos minerais, e transformando-os em outros. No caso do quartzo, este mineral é quase que incólume a estas reações, sendo os feldspatos, os plagioclásios mais que os potássicos, susceptíveis de se alterarem, como visto nas análises petrográficas.

\section{REFERÊNCIAS BIBLIOGRÁFICAS}

AIRES-BARROS, Luis. Alteração e alterabilidade das rochas, Lisboa, 1991.

Geobank.sa.cprm. gov.br, acesso em 28/09/2016.

Geodinâmica.no.sapo.pt./html, acesso em 28/09/2016.

LAGE, M. C. S. M. (2002). Contribuição da arqueoquímica para o estudo da arte rupestre. In: Fumdhamentos.Fundação
Museu do Homem Americano. V. 1, n. 2. São Raimundo Nonato - Piauí, (255-264).

LAGE, M. C. S. M. (2003). Os pigmentos pré-históricos de grafismos rupestres do sertão central do Ceará: análise química e reconstituição da técnica de realização. In: Fumdhamentos. Fundação Museu do Homem Americano. V. 1, n. 3 São Raimundo Nonato - Piauí, (147-161).

LAGE, M. C. S. M.; BORGES, J. F.; ROCHA Jr., S. Sítios de Registros Rupestres: Monitoramento e Conservação. MEME, Revista de Humanidades, Publicação do Departamento de História e Geografia da Universidade Federal do Rio Grande do Norte. Caicó, V. 06. N. 13, dez.2004/jan.2005.

MASCARENHAS, J. C.; BELTRÃO, B. A.; SOUZA JR., L. C.; MORAIS, F.; MENDES, V. A.; MIRANDA, J. L. F. (Organizadores). Projeto cadastro de fontes de abastecimento por água subterrânea. Diagnóstico do município de Ingá, estado da Paraíba. Recife, CPRM/PRODEEM, 2005.

RAMOS, Ana Catarina T. O sítio pré-histórico rupestre Pedra do Alexandre em Carnaúba dos Dantas, RN: estudo dos pigmentos. 1995. 107f. Dissertação (Mestrado em História) Programa de Pós-Graduação em História, Universidade Federal de Pernambuco, Recife, 1995.

Contribuição ao

10. Simpósio Brasileiro de Caracterização e Conservação da Pedra 14 a 16 de dezembro de 2016, Congonhas - MG

Nota:

É de responsabilidade da comissão editorial do Simpósio a revisão gramatical, ortográfica, de citações e referências bibliográficas. As normas de submissão podem se diferenciar das desta revista. 